\title{
The Basics Of Leadership: Understanding Leadership Attribute Assessment And Development
}

Richard L. Henderson, University of the Incarnate Word, USA Ms. Jia-Jing Jien, Ph.D. Candidate, University of the Incarnate Word, USA

\begin{abstract}
This exploratory study of leadership as a social-psychological process identifies and measures the perceived level of critical attributes that must be held by the leader in order for the leadership process to be effective. Leadership research literature was reviewed to discover the twelve most commonly agreed to primary attributes. Attributes were analyzed and categorically assigned as having either a cognitive or an affective basis of development. Data was collected and analyzed relative to the perceived level of effectiveness of each attribute by the leader and the group involved in the process. Qualified conclusions and recommendations for further are included.
\end{abstract}

Keywords: Leadership Development, Leadership Process, Leadership Attributes

\section{INTRODUCTION}

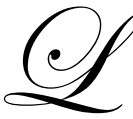
eadership is a difficult concept set to understand. The evidence of this statement is apparent in the several decades of research dedicated to the effort, the variety of competing theory base, and the myriad of questions that remain unanswered with respect to the idea of leadership. One plausible reason may be the fact that leadership is a complicated social-psychological process made up of a host of component parts that are also relatively complicated ideas.

There seems to be something of a renaissance in the notion of research related to the identification and assessment of leadership traits or skills. The question of whether the traits are derived from one's environment, genetic code, or learned in a formal or an informal way seems less important than the degree to which an individual possesses a particular trait or skill, and the question of whether or not the trait or skill is present in sufficient measure and quality to be effectively manifested when it is demanded by the leadership process. Additionally, the separation of traits from skills may also be seen as somewhat superfluous in the context of the current crises level need to develop effective leaders across the globe. Traits are defined by some researchers as qualities of a personality that are largely stable and fixed and therefore not especially amenable to change (Northouse, 2004). However, in the context of the leadership process, the question of development is often an important issue. Is the enhanced outgoing or assertive personality trait or attribute a result of a highly developed skill, such as communication, or is the superior capacity or attribute of problem solving a result of a substantially developed skill in conceptual transfer or an enhanced crystallized cognitive ability (Connelly et al., 2000)? Simply put, Traits may also develop, along with skill development or perhaps as a result of skill development. Additionally, the development of one skill may well contribute to another, or may contribute to an individual's overall capacity to exercise the process of leadership. As indicated in the above mentioned examples, measurable increases in what has been referred to as somewhat discrete personality traits may very well be enhanced in individuals as they develop the particular skills that are cognitively or affectively linked to a particular trait. Therefore, a reasonable contention may be that phenomenon referred to by various researchers as either skills or traits contributes to necessary attributes that allow an individual to see her/himself, and him/her to be seen by his/her followers as an effective leader. Moreover, the classification as well as the origin is of little consequence to reality of an effective leader within the process. 
It is important then, to isolate an exploratory list of discrete attributes that are well established as critically important contributors to effective leadership processes and analyze the perception of their measure within an individual, by the leader or potential leader and by the followers or group that is working with that individual.

The purpose of this research is then to analyze a selected exploratory list of the attributes that are considered essential for an effective leadership process and analyze their measure held by an individual leader, as perceived by the individual leader or potential leader and the followers or group working with that individual.

The research literature seems to call for the above listed purpose in order to move forward in the process view of leadership. Moreover, by initially focusing exclusively on the leader, the leadership attribute approach provides an in-depth understanding of the leader responsibility in the process. Finally, and probably most importantly, this approach has provided a way for leaders and prospective leaders to evaluate themselves and develop or further develop the attributes that are found to be challenges for them.

In a recent article entitled The Future of Leadership Research, Gordon and Yukl, described several problems with research in the area of leadership. One of their contentions is that, ".....................the majority of leadership theories focus on outcome prediction, rather than explaining the underlying process of leadership" (Gordon \& Yukl, 2004). It seems appropriate then, as a primary step, to return to the trait/skill/attribute view of the leadership phenomenon, select a set of attributes that are considered to be inextricably linked to leadership in the research literature, and assess the operational level of each of these essential attributes and analyze their perceived development so as to better understand the basic requirements for effective leadership as a process, rather than as a set of behaviors related to some mystical or spiritually charismatic personality.

Yukl's characterization of leadership as a phenomenon containing a "black box" (Gordon \& Yukl, 2004) that holds the elements (attributes) that are necessary for effectively leading would also suggest that an essential step in the research process would be to catalog and measure the perceived strength of the critical elements or attributes contained in the black box and analyze them in order to determine what measure and what quality of each of them is necessary for an effective leadership process.

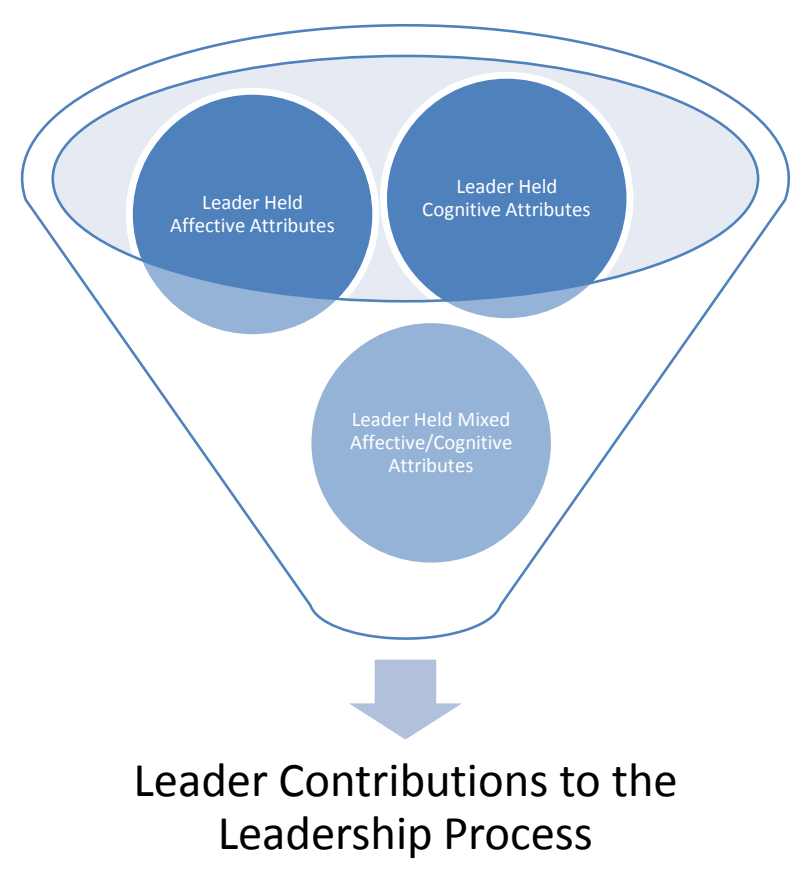


Even though the trait approach has, thus far, failed to provide a definitive list of traits that scholars and practitioners can agree on, the idea of a critical set of traits is appealing because it fits clearly into the popular idea that leaders are somehow selected people who are out front, leading the way in organizations, or society (Northouse, 2007). Moreover it is possible to select a set of widely acceptable contributing attributes that are necessary for an effective leadership process. The long list of attributes, sometimes called traits and sometimes referred to as skills in the research literature has been reviewed and a selected inventory of the twelve (12) most frequently agreed to attributes appear as the initial set to be analyzed in this research. Additionally, it seems important to note the nature of each attribute as either a cognition based or an affect based conceptual set.

Those attributes most frequently agreed to as critical in the literature include 1) facility for interpersonal relations (affective), 2) facility for group relations or group facilitation (cognitive and affective) 3) facility for individual and group support (cognitive and affective), 4) facility for tolerance (primarily affective), 5) facility for conceptual understanding (cognitive), 6) facility for organization (cognitive), 7) facility for effective communication (affective and cognitive), 8) facility for effective prioritization (cognitive), 9) facility for manifesting an appropriate personal image (cognitive and affective), 10) facility for creativity (affective and cognitive), 11) facility for problem diagnosis (cognitive) and finally 12) facility for personal flexibility (affective and cognitive).

\section{DEFINITIONS}

Interpersonal relations: Concerning or involving relationships between people (Encarta Dictionary)

Group Facilitation: Bringing A number of people or things together as a single whole (Encarta Dictionary)

Group Support: Providing the infrastructure or means to form a cohesive group or unit (Encarta Dictionary)

Tolerance: Acceptance of the differing views of other people, e.g. in religious or political matters, and fairness toward the people who hold these different views (Encarta Dictionary)

Conceptual Understanding: Ability to use knowledge and reasoning, intuition and perception (Encarta Dictionary)

Effective Communication: Accurate exchange of information between or among people e.g. by means of speaking, writing or using a common system, i.e. technology (Encarta Dictionary)

Organizational Ability: Ability with the creation of patterns, and the capacity to solve organizational problems (Encarta Encyclopedia)

Prioritization: Ranking things or ideas according to importance or urgency (Encarta Dictionary)

Image: A picture or likeness of someone or something produced either physically or formed in the mind of the beholder (Encarta Dictionary)

Creativity: The ability to use the imagination to develop new and original ideas or things (Encarta Dictionary)

Problem Diagnosis: The process of solving a question or puzzle, difficulty, or situation (Encarta Dictionary)

Flexibility: The ability to change or be changed according to needs or circumstances (Encarta Dictionary)

\section{METHODOLOGY}

Instrumentation was developed that incorporated the above listed attributes including a five (5) point Likert scale which was incorporated that ranged from (1) needs improvement, to (5) Excellent), as it was determined to measure the perceived level of effectiveness in each of the selected items. Through minimal changes in instrument wording, surveys were developed for individual leaders or prospective leaders as well as the followers or prospective followers for each individual. The instrumentation was checked for face validity and content validity as 
well as reliability through the use expert panels and pilot tests. The results of Chronbach's Alpha revealed a measure of .885 on the 12 item instrument in the composition designed for individuals and .883 in the composition for group perception. Therefore, the simple, but relatively strong perceptual survey instrumentation was then used to measure a variety of international student leadership groups. The initial reporting is from data analyzed submitted by a group (28 participants) of Mexican graduate students involved in a joint doctorial program in Organizational Leadership.

\section{FINDINGS}

Table 1.

Individual (\#1) Self Assessment

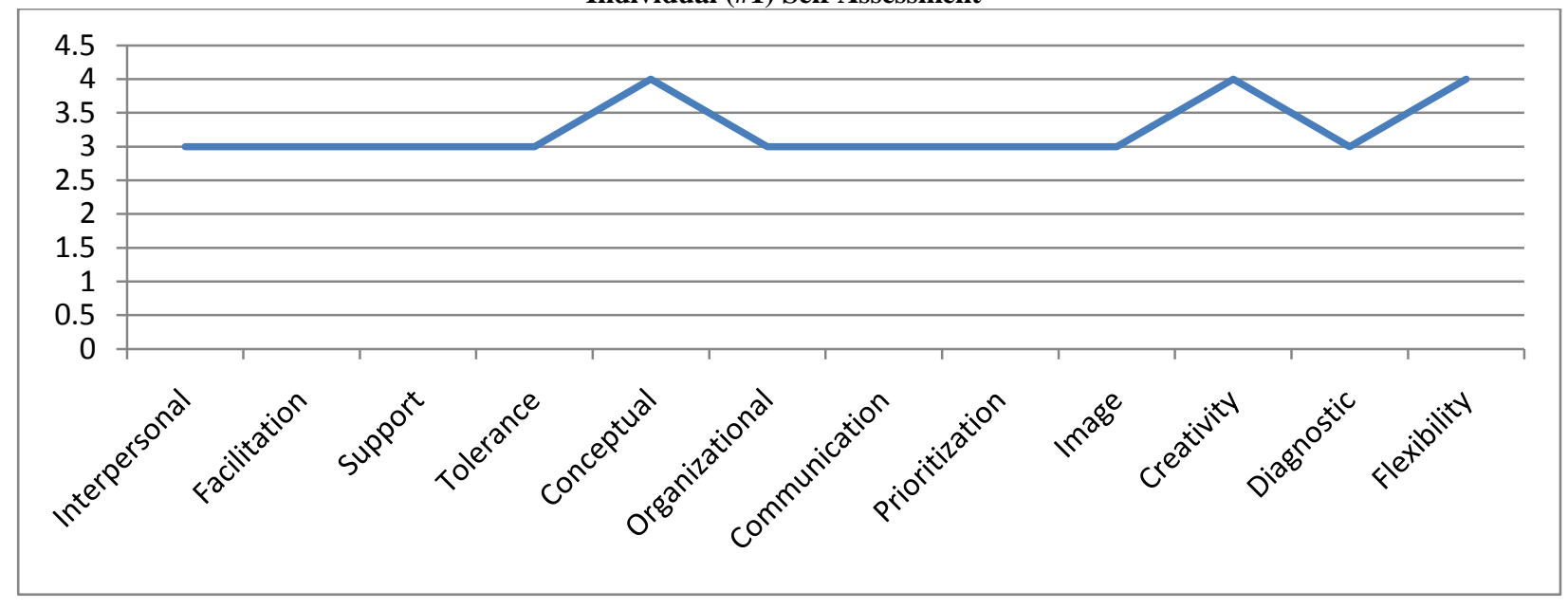

The Graphic display of data (Table 1), related to participant \#1, above, illustrates the self perception of the degree to which this individual's attributes are developed. It may be assumed that the context of the group has considerable influence on general or overall perception of the level of development by the individual.

Table 2.

Individual (\#1) Assessment by Group

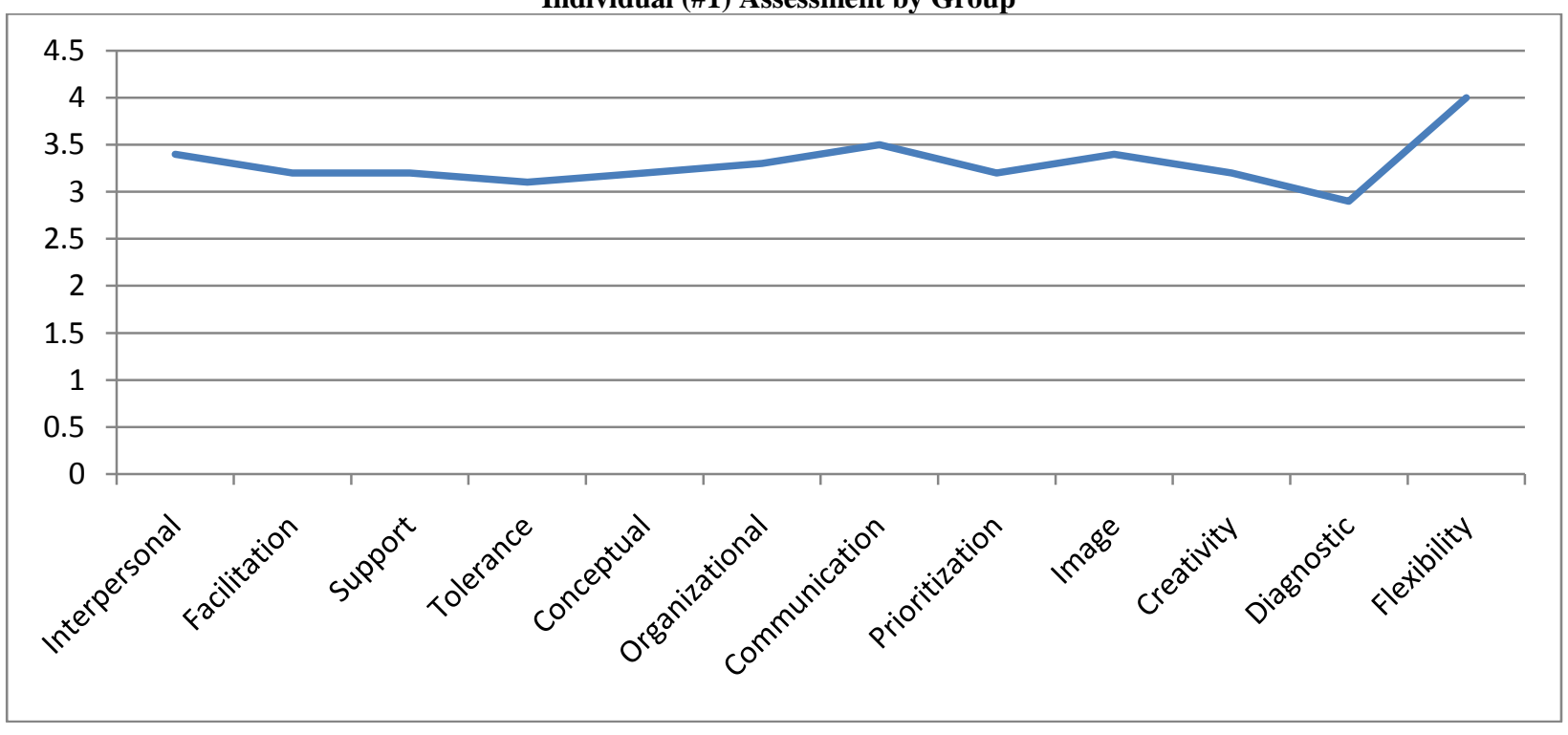


This second Graphic display of data (Table 2), also related to participant \#1, illustrates the group's perception of the degree to which this same individual's attributes are developed. Notably, there are differences between the individual's self perception and the group's perception of the same individual.

Table 3.

Individual (\#1) Self Assessment \& Assessment by Group Shown Together

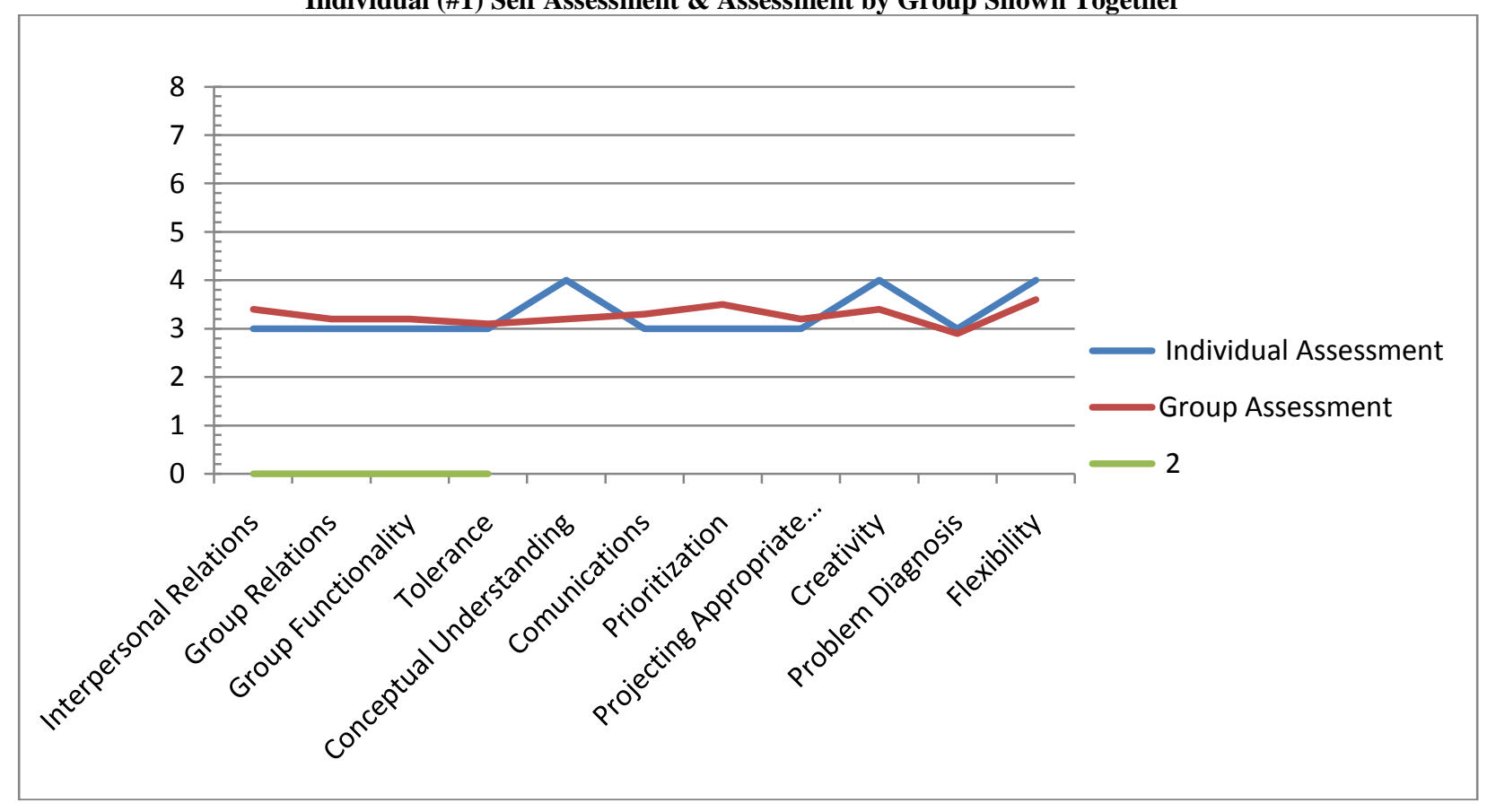

The differences are important for a variety of reasons. In the context of the leadership process in which all of the individuals are involved, the ideal picture of attribute development would indicate that all of the attributes were highly developed and that there was strong agreement between the leader and the group with respect to the perceived level of attribute development. Conversely, the significant need for improvement in any area, or a significant mismatch in the perceptions in any area indicates that the leader may not have an accurate perception of the development of his/her, own attributes compared to that of the group and the indication of significant differences in the group's perception about the individual's attribute development (especially when the groups perception is significantly lower) is an indication that the leader effectiveness in the process may be jeopardized.

\section{CONCLUSIONS \& DISCUSSION}

The categorical nomenclature attribute was selected to avoid the argumentation related to "trait" or "skill" and the controversy about whether the attributes are a result of genetics and environmental influences or a formal / informal learning environment. More importantly, the set of critical attributes are either cognitively or affectively based. Additionally, the recent burgeoning research related to emotional intelligence would seem to indicate that emotional or affective as well as cognitive or intellectual development may occur in individuals who are motivated to enhance their levels of performance in either source group.

The development of one attribute may contribute to the effectiveness of another attribute, or to the entire process of leadership. It is not clear how each of the attributes are developed in individuals or the extent that each of the discrete attributes is a contributor to the leadership process. However, it is difficult to imagine that communication, for example, does not contribute to all of the necessary attributes required for an effective leadership process and to the overall process as well. It may be that the attributes are compelled to operate 
collectively in order for the leadership process to be effective, or that the required level of operation of each attribute may be contingent on the setting, the sociology of the group involved, or a combination thereof. Further research related to necessary attribute combination would be helpful in answering that important question.

It seems clear that a significant deficiency, or a major mismatch in the perceptions of the operational level of each of the discretely measured attributes between the leader and the group will detract from the leadership process in such a way so as to deteriorate the leadership process and intended function. It is therefore important to understand the perceived operational level of critical attributes. To that end, a conscience understanding of the perceived level of effectiveness in the various attributes by the individual leader and the group working with that individual is critically important to the efficacy of the process of leadership. If the data suggest necessary improvement, an individual may then seek to improve his/her facility for a given attribute or, at the very least, demonstrate to the group that she/he has an effective command thereof.

Finally, it may also be important, as a recommendation for further research, to identify, analyze, and fully understand the sociological attributes held by the group involved in the leadership process. Group attributes such as "positive group climate", the general level of education of a group, the technical skills held by the group, the cultural attributes of the group, as well as other sociological attributes are no doubt critically important for the function of leadership when it is viewed as a process. Additional research related to group attributes will be necessary in order to fully understand the dynamic and multifaceted process of leadership.

\section{AUTHOR INFORMATION}

Dr. Richard L. Henderson is a Professor in and Coordinator for the Organizational Leadership Programs at the University of the Incarnate Word. He has CEO experience as a practicing Executive for Education Institutions and as a Graduate Professor and Researcher. He has authored books, book chapters, international research articles, and successful grants in Organizational Policy, Professional Ethics, and Leadership Research \&Development.

Ms. Jia-Jing Jien is a doctoral student in the Organizational Leadership Program in the Dreeben School of Education at the University of the Incarnate Word, San Antonio, TX, USA. She is also an Instructor in the Department of Business Administration at St. John's University in Taipei, Taiwan. She has an MS in Journalism and Mass Communication and an MBA from Iowa State University, Ames, IA, USA. Her research interests include marketing research, integrated marketing communication and effective leadership.

\section{REFERENCES}

1. Bass, B. M. (1990). Bass and Stogdill's handbook of leadership: A survey of theory and research. New York: Free Press.

2. Connelly, M. S., Gilbert, J.A., Zaccaro, S.J., Threlfall, K.V., Marks, M.A., \& Mumford, M.D. (2000) Exploring the relationship of leadership skills and knowledge to leader performance. Leadership Quarterly, 11 (1), 65-86.

3. Goldberg. L.R. (1990) An alternative "description of personality": The big-five factor structure. Journal of Personality and Social Psychology, 59, 1216-1229.

4. Goleman, D. (1998) Working with emotional intelligence. New York: Bantam.

5. Gordon, A. \& Yukl, G. (2004) The future of leadership research: Challenges and Opportunities. Zeitschrift Fur Personalforschung, 18. Jg., Heft 3 p. 359-365. ABI/INFORM Global.

6. $\quad$ Katz, R.L. (1955). Skills of an effective administrator. Harvard Business Review, 2, 289-3.

7. Kirkpatrick. S.A., \& Locke, E.A. (1991) Leadership: Do traits matter? The Executive, 5, 48-60.

8. Mayer, J.D., \& Salovey, P. (2000). Selecting a measure of emotional intelligence: The case for ability scales. In R. Bar-On \& J.D.A. Parker (Eds.), The handbook of emotional intelligence. New York: JosseyBass.

9. $\quad$ Northouse, Peter G. (2007) Leadership Theory and Practice._Sage Publications Inc. London. 